\title{
Efficiency of Metarhizium anisopliae in the control of Meloidogyne incognita in banana and coffee crops
}

\author{
Claudio Marcelo Gonçalves de Oliveira ${ }^{1^{*}}(\mathbb{D})$, Juliana Magrinelli Osório Rosa ${ }^{2}$, Rhayane Resende Pillat ${ }^{3}$, \\ José Eduardo Marcondes de Almeida ${ }^{1}$ [D
}

${ }^{1}$ Instituto Biológico/IB, Campinas, SP, Brasil

${ }^{2}$ Instituto Biológico Consórcio Brasileiro de Pesquisa e Desenvolvimento do Café/CBP \& D-Café, Campinas, São Paulo, Brasil

${ }^{3}$ Pontifícia Universidade Católica de Campinas/PUCC, Campinas, São Paulo, Brasil

Contact authors: claudiomarcelo.oliveira@sp.gov.br; julianamagrinelli@hotmail.com; nany_pillat@hotmail.com; jose.marcondes@sp.gov.br

Received in August 13, 2021 and approved in October 27, 2021

\section{ABSTRACT}

Banana and coffee are crops damaged by the root-knot nematode (Meloidogyne incognita). Thus, the objective of this research was to study the efficiency of biological products in the control of $M$. incognita in both crops. Four experiments were carried out in a greenhouse, in a completely randomized design, inoculating banana and coffee plants with 2000 eggs and second-stage juveniles of $M$. incognita. In experiment 1 , each plot was constituted of a banana seedling cv. Prata Anã. The treatments, applied around each seedling, contained the fungi Metarhizium anisopliae, from the collection kept in the Biological Control/CAPSA, IB, and Pochonia chlamydosporia (the commercial product Rizotec ${ }^{\circledR}$ ). In experiment 2 , coffee seedlings cv. Arara were treated in a single dose with $M$. anisopliae and P. chlamydosporia. In experiments 3 and 4, coffee seedlings cv. Mundo Novo were treated alone or mixed with M. anisopliae and Purpureocillium lilacinum. Based on the results obtained after 150 days of inoculation, it was concluded that M. anisopliae and P. chlamydosporia have usage potential for biological control of $M$. incognita in bananas and coffee. In the coffee crop, $P$. chlamydosporia showed $81 \%$ efficiency in reducing the population of $M$. incognita, whereas for $M$. anisopliae, the efficiency was up to $76.9 \%$. However, there was no difference between treatments with biological control agents in relation to fresh root weight and dry weight of the aerial part of the coffee plants.

Key words: Biological control; Fungi; Nematodes.

\section{INTRODUCTION}

Among the phytosanitary problems that affect banana and coffee crops, the root knot nematode Meloidogyne incognita is responsible for one of the greatest economic losses (Lopes; Ferraz, 2016). The control of this species requires the development of alternatives to improve integrated management strategies that reduce the use of pesticides and that are environmentally safe, like biological control agents.

Several fungi are efficient biological agents against plant parasitic nematodes, which contribute to alleviate the losses caused by these parasites. At the moment, there are different commercial products denominated bionematicides or biodefensives that encompass these formulations, highlighting the fungi Purpureocillium lilacinum (=Paecilomyces lilacinus), Pochonia chlamydosporia and Trichoderma spp., which are recommended for the control of Meloidogyne and Pratylenchus species, considered the most harmful nematodes to most plants cultivated in Brazilian agriculture. These fungi use the mechanisms of parasitism of eggs and female nematodes, antibiosis and resistance induction (Arieira et al., 2013; Dallemole-Giaretta et al., 2015; Sahebani; Hadavi, 2008; Sharon et al., 2007).

Additionally, the international literature registers the potential for biocontrol of nematodes with the fungus Metarhizium anisopliae. In the Boyer-Ahmad region, Iran, Ghayedi and Abdollahi (2013) evaluated in vitro the antagonistic efficiency of the fungus and it was observed that $M$. anisopliae was pathogenic to Heterodera avenae, reaching $47 \%$ efficiency. In India, based on the results reported by Abdollahi (2018), the combination of M. anisopliae IMI 330189 and organic matter from oak remains caused more than $90 \%$ reduction in the reproduction of $M$. javanica, parasitizing tomatoes. In Brazil, the only information available was the experiment under field conditions developed by Rossi et al. (2006), who reported the suppressive effect of $M$. anisopliae on the population densities of Pratylenchus and Meloidogyne in sugarcane.

The most common mode of action of $M$. anisopliae in insects is by contact, when the conidium enters the tegument, germinates under the conditions of $\mathrm{pH}$, humidity and temperature of the host's body, produces enzymes such as chitinases, lipases and proteinases, favoring conditions for the fungal mycelium to penetrate the host insect (Leite et al., 2003). However, for nematodes the exact mode of action of $M$. anisopliae is still unknown, but probably similar to other fungi with sticky conidia. Thus, the conidia germinate, parasitize and kill the nematode by direct penetration and producing infective hyphae within the nematode's body. It is noteworthy that before any direct attack on the host, the fungus produces destruxin A and destruxin B that can kill the host, making the fungus $M$. anisopliae an important bionematicide (Devi, 2018).

In view of the scarcity of information, the objective of this work was to study the efficiency of the action of biological 
products, with emphasis on $M$. anisopliae, in the control of $M$. incognita in banana and coffee plants.

\section{MATERIAL AND METHODS}

Localization. Four experiments were carried out in a controlled temperature greenhouse, located at the Laboratory of Nematology, Advanced Center for Research in Plant Protection and Animal Health (CAPSA), Biological Institute, in the city of Campinas, SP, Brazil, with coordinates S 22 $2^{\circ} 54^{\prime} 498^{\prime \prime}$ and WO $47^{\circ} 00^{\prime} 842$ " and altitude $707 \mathrm{~m}$, from January 2019 to April 2021.

Obtaining the inoculum. The population of $M$. incognita used in the experiments was isolated from coffee trees and kept in a greenhouse at the Biological Institute, Campinas, SP. Eggs and second-stage juveniles (J2) of $M$. incognita used as inoculum in the experiments were obtained from roots of tomato and coffee plants by Coolen and D'Herde (1972) methodology. The number of specimens in the water suspension obtained was estimated using a Peters counting slide under a light microscope.

\subsection{Experiment 1 - M. incognita control in banana cv. Prata Anã}

The experimental design was completely randomized, with four treatments and four replicates. Each plot consisted of one banana seedling cv. Prata Anã, produced in vitro, transplanted to a 5-liter pot, containing autoclaved substrate. On the same day of the transplanting, each plant was inoculated with 2000 eggs and J2 of M. incognita and treated with the biological control agents. The treatments were applied in a single dose, via suspension simulating an application by drench around each seedling and contained the fungi $M$. anisopliae, at a dose of $4.8 \mathrm{~kg} / \mathrm{ha}$, from the collection maintained at the Biological Control Reference Laboratory Unit/CAPSA, IB, registered under number IBCB 425 , and $P$. chlamydosporia, strain Pc 10, at a dose of $4.0 \mathrm{~kg} / \mathrm{ha}$ (the commercial product Rizotec $^{\circledR}$ ). For comparison, a control (without treatment) was included and Carbofuran 100G (4 g/plant) was used as chemical control standard, applied in a single dose during the transplant.

\subsection{Experiment 2 - control of $M$. incognita in coffee cv. Arara - one application}

The experimental design was completely randomized, with four treatments and four replicates. Each plot consisted of one plant per 3.8-liter pot, containing autoclaved substrate. Just after transplanting the coffee seedlings $\mathrm{cv}$. Arara (seedlings with four pairs of true leaves), the biological agents were applied over the entire surface of the soil and incorporated using a spatula. The treatments were applied via suspension containing the fungi M. anisopliae, isolated IBCB 425 at a dose of $70 \mathrm{~g} /$ ha, (commercial product Metarriz Plus ${ }^{\circledR}$, formulation WP) and P. chlamydosporia, strain Pc 10 (commercial product Rizotec, ${ }^{\circledR}$
$4.0 \mathrm{~kg} / \mathrm{ha}$ ). For comparison, two controls (with and without nematodes) were used. The products were applied in a single dose, on the same day as the inoculation of nematodes, by drench. Then, the inoculation of the nematode M. incognita was carried out in a hole approximately $2 \mathrm{~cm}$ deep. Each plant was inoculated with 2000 eggs and $\mathbf{J} 2$ of $M$. incognita.

\subsection{Experiment 3 - control of $M$. incognita in coffee cv. Mundo Novo - three applications}

The experimental design was completely randomized, with five treatments and four replicates. Each plot contained one plant per 3.8-liter pot, containing autoclaved substrate. Just after transplanting the coffee seedlings cv. Mundo Novo (seedlings with four pairs of true leaves), the biological agent was applied on the entire surface of the soil and then the soil was turned over to incorporate the product. Then, the inoculation of the nematode $M$. incognita was carried out in a hole of approximately $2 \mathrm{~cm}$ deep. Each plant was inoculated with 2000 eggs and $\mathrm{J} 2$ of $M$. incognita.

Two biological control agents were tested alone and in a mixture: $M$. anisopliae $(2.4 \mathrm{~kg} / \mathrm{ha}$, isolate IBCB 425$)$ and $P$. lilacinum (200 g/ha). For comparison, two controls (with and without nematodes) were used. The drench application of the products was carried out on three dates: on the same day of the nematodes inoculation, at 7 and 21 days after inoculation (DAI).

\subsection{Experiment 4 - control of $M$. incognita in coffee plants cv. Novo Mundo - six applications}

The experimental design, treatments and doses were the same as in experiment 3, with two biological control agents tested alone and in a mixture: $M$. anisopliae $(2.4 \mathrm{~kg} / \mathrm{ha}$, isolated IBCB 425) and P. lilacinum (200 g/ha), but there were six drench applications of the products instead of three: one week before inoculation, on the same day of inoculation and at 7, 14, 28 and 42 DAI. Each coffee seedlings cv. Mundo Novo (seedlings with two pairs of true leaves) was inoculated with 2000 eggs and $\mathrm{J} 2$ of $M$. incognita.

\subsection{Final population, nematode reproduction factor and plant development variables}

In the four experiments, approximately 150 DAI, the nematodes in the plant roots were extracted by the method of Coolen and D'Herde (1972). The final population (FP) was obtained by counting the nematodes on Peters slides using a light microscope. The nematode reproduction factor (RF) was estimated for each replicate, taking the final population (FP) and dividing it by the initial population ( $\mathrm{Pi}=2000$ nematodes).

In addition, the influence of the treatments on the development of banana and coffee plants was verified, evaluating the height of the plants, the fresh weight of the roots (FWR) and dry weight of the aerial part (DWAP). 


\subsection{Statistical analysis}

The values of the variables: plant height, FWR, DWAP and population density of $M$. incognita in the banana and coffee roots (final population) were subjected to analysis of variance using the Sisvar program (Ferreira, 2011). After analysis, the treatment means were compared by the LSD test at 5\% significance. In addition, the efficiency percentage of the evaluated products $(\mathrm{E} \%)$ in relation to the control with nematodes was determined using the Abbott formula.

\section{RESULTS}

\subsection{Experiment 1}

At 150 DAI (Table 1), the final population of $M$. incognita in treatments with $M$. anisopliae and P. chlamydosporia did not differ statistically from the control with nematodes. However, for P. chlamydosporia the efficiency (E\%) of the product in reducing the population of $M$. incognita was $49 \%$, with $\mathrm{RF}=6.2$, while $M$. anisopliae provided a population reduction of $66 \%$ and $\mathrm{RF}=4.2$.

It was found that there was a statistical difference between the treatments with the two biological control agents in relation to the control plants for plant height and fresh weight of the roots (Table 1). For shoot dry weight, only M. anisopliae differed from the control, indicating that this agent has a stimulating action, which favors the development of roots and shoots of banana plants.

\subsection{Experiment 2}

The results of experiment 2 are shown in Table 2. Metarhizium anisopliae and P. chlamodosporia may have nematicide effects against M. incognita in coffee cv. Arara as the final population of $M$. incognita in the treatments of these two agents differed statistically from the control with nematodes. In a single application, at a ratio of $4 \mathrm{~kg} / \mathrm{ha}, P$. chlamodosporia had $81 \%$ efficiency (E\%) in reducing the population of $M$. incognita, with 1.6 reproduction factor (RF), while $M$. anisopliae $(70 \mathrm{~g} / \mathrm{ha}$ ) had $73 \%$ efficiency in reducing the population of $M$. incognita and $\mathrm{RF}=2.3$.

According to the data of the coffee plant development variables, it was found that there was no statistical difference between treatments with biological control agents in relation to the control with nematode for root fresh weight and shoot dry weight (Table 2).

\subsection{Experiment 3}

Experiment 3 confirmed the results presented in the previous experiment and clearly show that $M$. anisopliae has a nematicidal effect against $M$. incognita in coffee cv. Mundo Novo (Table 3). The biological agent $M$. anisopliae alone had $76.9 \%$ efficiency in reducing the population of $M$. incognita and $\mathrm{RF}=1.2$. When it was used together with the other biological agent (M. anisopliae + P. lilacinum $)$ the efficiency was lower $(\mathrm{E}=32.1 \%)$. It was observed that the treatment with P. lilacinum, used alone did not differ statistically in the final population of $M$. incognita compared to plants infested with nematodes (control with nematode), demonstrating that P. lilacinum was not effective in controlling this nematode in coffee $\mathrm{cv}$. Mundo Novo.

Table 1: Mean population density values of eggs and juveniles of Meloidogyne incognita present in banana roots [final population $(F P)]$, control efficiency $(E \%)$ and reproduction factor $(R F)$, height $(H)$, fresh weight of roots (FWR) and dry weight of the aerial part (DWAP) of banana cv. Prata Anã, 150 days after inoculation with M. incognita. Average of four replicates.

\begin{tabular}{|c|c|c|c|c|c|c|}
\hline Treatments & FP & $\mathrm{E} \%$ & $\mathrm{RF}$ & $\mathrm{H}(\mathrm{cm})$ & FWR $(g)$ & DWAP $(g)$ \\
\hline Control with nematode & $24114 b$ & 0 & 12.1 & $38.3 b$ & $91.8 \mathrm{a}$ & $262.2 b$ \\
\hline Metarhizium anisopliae $(4.8 \mathrm{~kg} / \mathrm{ha})$ & $8311 \mathrm{ab}$ & 66 & 4.2 & $46.4 \mathrm{c}$ & $166.4 b$ & $349.4 c$ \\
\hline Pochonia chlamydosporia $(4.0 \mathrm{~kg} / \mathrm{ha})$ & $12383 \mathrm{ab}$ & 49 & 6.2 & $45.8 \mathrm{c}$ & $198.4 b$ & $320.6 \mathrm{ab}$ \\
\hline Carbofuran 100G & $890 \mathrm{a}$ & 96 & 0.4 & $28.4 \mathrm{a}$ & $115.3 \mathrm{a}$ & $193.4 b$ \\
\hline
\end{tabular}

Means followed by the same letters within the columns did not differ statistically at the $5 \%$ probability level by the LSD test.

Table 2: Mean population density values of eggs and juveniles of Meloidogyne incognita present in coffee roots [final population $(F P)]$, control efficiency $(E \%)$ and reproduction factor $(R F)$, height $(H)$, fresh weight of roots $(F W R)$ and dry weight of the aerial part (DWAP) of coffee cv. Arara, 150 days after inoculation with M. incognita. Average of four replicates.

\begin{tabular}{|c|c|c|c|c|c|}
\hline Treatments & $\mathrm{FP}$ & $\mathrm{E} \%$ & RF & FWR (g) & DWAP $(g)$ \\
\hline Control without nematode & $0 \mathrm{a}$ & - & 0 & $16.9 \mathrm{a}$ & $10.6 \mathrm{a}$ \\
\hline Control with nematode & $17100 \mathrm{c}$ & - & 8.6 & $8.0 \mathrm{~b}$ & $7.2 \mathrm{a}$ \\
\hline Pochonia chlamydosporia $(4.0 \mathrm{~kg} / \mathrm{ha})$ & $3230 b$ & 81 & 1.6 & $8.2 b$ & $8.4 \mathrm{a}$ \\
\hline Metarhizium anisopliae (70g /ha) & $4575 b$ & 73 & 2.3 & $8.8 \mathrm{~b}$ & $8.6 \mathrm{a}$ \\
\hline
\end{tabular}

Means followed by the same letters within the columns did not differ statistically at the $5 \%$ probability level by the LSD test. 
According to the data of the plant development variables of the present experiment, it was found that there was no statistical difference between the treatments with biological control agents in relation to the control, although, on average, the plants that received the treatments with biological agents were higher and with greater root volume compared to the control with nematode.

\subsection{Experiment 4}

In this study, there was no difference between treatments and control with nematodes for FP, demonstrating that $M$. anisopliae has not a nematicide effect against $M$. incognita in coffee cv. Novo Mundo (Table 4). This result differed from the previous experiments (Experiments 2 and 3 ) and did not confirm them. The biological agent $M$. anisopliae, alone, showed only $46 \%$ efficiency in reducing the population of $M$. incognita and $\mathrm{RF}=1.3$. When used together with the other biological agent (M. anisopliae $+P$. lilacinum), the efficiency was similar. According to the data of the plant development variables of the present experiment, it was found that there was no statistical difference was observed between the treatments with biological control agents in relation to the control, except for the FWR of $M$. anisopliae $(\mathrm{FWR}=1)$ which statistically it was lower compared to the control $(\mathrm{FWR}=1.8)$.

\section{DISCUSSION}

The fungus $M$. anisopliae, although well known for being a parasite of insects Mahanarva fimbriolata and
M. posticata and having its commercial production well established (Goble; Almeida; Conlong, 2017), has been little studied in the control of nematodes. However, there are reports of its efficiency in reducing the reproduction of $M$. javanica parasitizing tomatoes in India (Abdollahi, 2018). In the present study, based on four experiments conducted under controlled conditions, it was observed the efficiency of $M$. anisopliae and two other fungi ( $P$. chlamydosporia and P. lilacinum) in controlling $M$. incognita in banana and coffee crops.

Banana plants treated with a single dose of $M$. anisopliae or P. chlamydosporia showed greater vegetative development compared to the control. These agents have a stimulating action (phytotonic effect), acting favourably on the development of roots and shoots of banana, in addition to the effect on the population reduction of $M$. incognita, with a population reduction of up to $66 \%$. Although there is no information available on the use of $M$. anisopliae or P. chlamydosporia previously, several reports have demonstrated the efficacy of biological control agents in the management of Meloidogyne spp. in banana. For example, in South Africa, a commercial product based on the soil fungus $P$. lilacinum has been used to reduce the number of nematodes and shorten the period from flowering to banana harvest (Daneel; De Waele, 2017). This egg parasitic fungus has also acted as an antagonist of root knot nematodes in India. Applied at a dose of $15-20 \mathrm{~g} /$ plant, the biological product managed to reduce the gall index, number of eggs and population density of $M$. incognita in banana plants (Sundararaju et al., 2003).

Table 3: Mean population density values of eggs and juveniles of Meloidogyne incognita present in coffee roots [final population $(F P)]$, control efficiency $(E \%)$ and reproduction factor $(R F)$, height $(H)$, fresh weight of roots $(F W R)$ and dry weight of the aerial part (DWAP) of coffee cv. Mundo Novo, 150 days after inoculation with M. incognita. Average of four replicates.

\begin{tabular}{ccccccc}
\hline Treatments & FP & E\% & RF & H $(\mathrm{cm})$ & FWR $(\mathrm{g})$ & DWAP $(\mathrm{g})$ \\
\hline Control without nematode & $0 \mathrm{a}$ & - & 0.0 & $30.4 \mathrm{a}$ & $5.1 \mathrm{a}$ & $3.9 \mathrm{a}$ \\
Control with nematode & $10788 \mathrm{~b}$ & - & 5.4 & $24.1 \mathrm{a}$ & $3.3 \mathrm{a}$ & $2.3 \mathrm{a}$ \\
Metarhizium anisopliae $(2.4 \mathrm{~kg} / \mathrm{ha})$ & $2488 \mathrm{a}$ & 76.9 & 1.2 & $29.3 \mathrm{a}$ & $6.2 \mathrm{a}$ & $3.7 \mathrm{a}$ \\
Purpureocillium lilacinum $(200 \mathrm{~g} / \mathrm{ha})$ & $19738 \mathrm{~b}$ & -83.0 & 9.9 & $28.8 \mathrm{a}$ & $5.5 \mathrm{a}$ & $3.5 \mathrm{a}$ \\
M. anisopliae + P. lilacinum & $7320 \mathrm{ab}$ & 32.1 & 3.7 & $25.9 \mathrm{a}$ & $5.9 \mathrm{a}$ & $3.2 \mathrm{a}$ \\
\hline
\end{tabular}

Means followed by the same letters within the columns did not differ statistically at the $5 \%$ probability level by the LSD test.

Table 4: Mean population density values of eggs and juveniles of Meloidogyne incognita present in banana roots [final population $(F P)]$, control efficiency $(E \%)$ and reproduction factor $(R F)$, height $(H)$, fresh weight of roots $(F W R)$ and dry weight of the aerial part (DWAP) of coffee cv. Mundo Novo, 150 days after inoculation with M. incognita. Average of four replicates.

\begin{tabular}{ccccccc}
\hline Treatments & FP & E\% & RF & H $(\mathrm{cm})$ & FWR $(\mathrm{g})$ & DWAP $(\mathrm{g})$ \\
\hline Control without nematode & $0 \mathrm{~b}$ & - & 0 & $14.5 \mathrm{ab}$ & $1.3 \mathrm{ab}$ & $1.1 \mathrm{~b}$ \\
Control with nematode & $4795 \mathrm{a}$ & 0 & 2.4 & $14.9 \mathrm{ab}$ & $1.8 \mathrm{bc}$ & $0.9 \mathrm{~b}$ \\
Metarhizium anisopliae $(2.4 \mathrm{~kg} / \mathrm{ha})$ & $2573 \mathrm{ab}$ & 46 & 1.3 & $12.5 \mathrm{a}$ & $1.0 \mathrm{a}$ & $0.6 \mathrm{ab}$ \\
Purpureocillium lilacinum $(200 \mathrm{~g} / \mathrm{ha})$ & $3735 \mathrm{ab}$ & 22 & 1.9 & $14.5 \mathrm{ab}$ & $2.0 \mathrm{c}$ & $0.8 \mathrm{ab}$ \\
M. anisopliae + P. lilacinum & $2595 \mathrm{ab}$ & 46 & 1.3 & $15.8 \mathrm{~b}$ & $2.0 \mathrm{c}$ & $1.1 \mathrm{~b}$ \\
\hline
\end{tabular}

Means followed by the same letters within the columns did not differ statistically at the $5 \%$ probability level by the LSD test. 
In the present study, M. anisopliae showed potential as biological control of $M$. incognita in coffee, by reducing the nematode population from $46.0 \%$ to $76.9 \%$, with the highest efficiency after three applications of the biological agent (at 0 , 7 and 21 DAI). Furthermore, while P. chlamydosporia showed high efficiency (81\%, experiment 2$)$, the other biological agent evaluated, $P$. lilacinum, was not efficient in controlling M. incognita (experiments 3 and 4). Currently, little is known about the use of antagonist fungi as biological agents in the control of nematodes in coffee, but there are studies that prove the efficiency of these agents. For example, when comparing P. lilacinum isolates from coffee plantations in the region of Londrina, PR, Cadioli et al. (2009) observed a decrease in the population of $M$. paranaensis in coffee trees cv. Icatu, in a greenhouse. Reductions of eggs in the root system were observed in all isolates. However, parameters such as increased growth of coffee trees, reduction of juveniles in the soil and decrease in root malformations were evident in specific isolates. Therefore, the importance of selecting these strains for an effective control was demonstrated. Thus, one of the explanations for the low control efficiency of $M$. incognita in coffee cv. Mundo Novo may be related to the virulence of the strain used in this study, with the need for future studies of pathogenicity to choose the biological agent with the highest virulence against this species of nematode in coffee. Santiago et al. (2006) studied the efficiency of $P$. lilacinum isolates from different regions and crops to control M. paranaensis in tomato, observing this virulence differentiation that act mainly in the reduction of the nematode population and in the survival of these organisms in the soil, desirable characteristics for a biocontrol agent.

According to Ghayedi and Abdollahi (2013), the mode of action of $M$. anisopliae in nematodes is still unknown, but it is probably similar to other fungi with adhesive spores, which can adhere to the nematode, germinate, penetrate directly through the cuticle and produce infective hyphae within the body cavity. In a pathogenicity test, the authors observed juveniles of Heterodera avenae parasitized by M. anisopliae. Also, has been reported that entomopathogenic fungi may to colonize the roots as asymptomatic endophytes. Metarhizium anisopliae is considered an entomopathogen and an endophyte in the soil, which can colonize plant root tissues, resulting in increased development and tolerance against pests and diseases (Altinok; Altinok; Koca, 2019; Sasan; Bidochka, 2012). However, future studies must be conducted to understand the mechanism of action in Brazilian populations of M. anisopliae. in promoting growth and reducing the nematode population.

A greater efficiency was observed with three applications of $M$. anisopliae than with six applications (Experiment 4). There are no studies clearly proving this issue, but it is possible that with the high concentration of $M$. anisopliae conidia, there is a competition between the germinated conidia that colonize the soil, with a decrease in parasitism in nematodes, but research is needed to confirm this hypothesis. Also, as M. incognita is a sedentary endoparasite nematode, the conidia no longer have access to the nematode inside the roots. Thus, the nematode is able to complete the cycle, explaining the RF above 1.

\section{CONCLUSIONS}

In conclusion, this study demonstrated that the fungi M. anisopliae and P. chlamydosporia have potential to be used in the biological control of $M$. incognita in banana and coffee crops. In the coffee plants, $P$. chlamydosporia showed $81 \%$ efficiency in reducing the population of $M$. incognita, while for $M$. anisopliae, the efficiency was up to $76.9 \%$. However, none of the biological control agents increased coffee plant development. Furthermore, the need for more in-depth studies is evident to better understand the interaction between agents used in biological control in order to reduce the population of the main nematode species within the coffee growing system.

\section{ACKNOWLEDGMENTS}

The authors thank Juliana Eulálio for technical assistance. The authors are indebted to the Brazilian Consortium for Coffee Research and Development (CBP and D-Café) and the National Council for Scientific and Technological Development (CNPq/PIBIC/IB) for research fellowships and the São Paulo Research Foundation (FAPESP) for research grants (PDIP-FAPESP process 2017/50334-3).

\section{AUTHORS' CONTRIBUTION}

CMGO wrote the manuscript, performed the experiment and conducted all statistical analyses, JMOR performed the experiment and co-wrote the manuscript, RRP performed the experiment and co-wrote the manuscript, JEMA supervised the experiment and co- wrote the manuscript. All authors reviewed and approved of the final version of the work.

\section{REFERENCES}

ABDOLLAHI, M. Application of Metarhizium anisopliae against Meloidogyne javanica in soil amended with oak debris. International Journal of Agricultural and Biosystems Engineering, 12(2):35-41, 2018.

ALTINOK, H. H.; ALTINOK, M. A.; KOCA, A. S. Modes of action of entomopathogenic fungi. Current Trends in Natural Sciences, 8(16):117-124, 2019.

ARIEIRA, C. R. D. et al. Induce resistance in the nematodes control. African Journal of Agricultural Research, 8(20):2312-2318, 2013. 
CADIOLI, M. C. et al. Efeito de isolados de Paecilomyces lilacinus no desenvolvimento de cafezais e na população de Meloidogyne paranaensis. Ciência e Agrotecnologia, 33(3):713-720, 2009.

COOLEN, W. A.; D'HERDE, C. J. A method for the quantitative extraction of nematodes from plant tissue. GHENT, Belgium: State Agriculture Research Center, 1972. $77 \mathrm{p}$.

DALLEMOLE-GIARETTA, R. et al. Pochonia chlamydosporia promotes the growth of tomato and lettuce plants. Acta Scientiarum Agronomy, 37(4):417423, 2015.

DANEEL, S. M.; DE WAELE, D. Nematode pests of banana. In: FOURIE, H. et al. Nematology in South Africa: A View from the 21st Century. Switzerland: Springer International Publishing, p. 359-371, 2017.

DEVI, G. Nematophagous fungi: Metarhizium anisopliae. International Journal of Environment, Agriculture and Biotechnology, 3(6):2110-2113, 2018.

FERREIRA, D. F. Sisvar: A computer statistical analysis system. Ciência e Agrotecnologia, 35(6):1039-1042, 2011.

GHAYEDI, S.; ABDOLLAHI, M. Biocontrol potential of Metarhizium anisopliae (Hypocreales: Clavicipitaceae), isolated from suppressive soils of Boyer- Ahmad region, Iran, against J2s of Heterodera avenae. Journal of Plant Protection Research, 53(2):165-171, 2013.

GOBLE, T.; ALMEIDA, J. E. M.; CONLONG, D. Microbial control of sugarcane insect pests. In: LACEY, L. A. Microbial control of insect and mite pest. San Diego: Elsevier, p.299-312, 2017.
LEITE, L. G. et al. Produção de fungos entomopatogênicos. Ribeirão Preto: Alexandre de Sene Pinto, 2003. 92p.

LOPES, E. A.; FERRAZ, S. Importância dos fitonematoides na agricultura. In: OLIVEIRA, C. M. G.; SANTOS, M. A.; CASTRO, L. H. S. Diagnose de fitonematoides. Campinas: Millennium, 2016. 14p.

ROSSI, C. E. et al. Efeito de inseticidas fitoquímicos e microbianos em nematóides da cana-de-açúcar. STAB, 24(3):6-8, 2006.

SAHEBANI, N.; HADAVI, N. Biological control of the rootknot nematode Meloidogyne javanica by Trichoderma harzianum. Soil Biology Biochemistry, 40(8):2016-2020, 2008.

SASAN, R. K.; BIDOCHKA, M. J. The insect-pathogenic fungus Metarhizium robertsii (Clavicipitaceae) is also an endophyte that stimulates plant root development. American Journal of Botany, 99(1):101-107, 2012.

SANTIAGO, D. C. et al. Seleção de isolados de Paecilomyces lilacinus (Thom.) Samson para controle de Meloidogyne paranaensis em tomateiro. Ciência Rural, 36(4):1055-1064, 2006.

SHARON, E. et al. Parasitism of Trichoderma on Meloidogyne javanica and role of the gelatinous matrix. European Journal of Plant Pathology, 118:247-258, 2007.

SUNDARARAJU, P.; SHANTHI, A.; SATHIAMOORTHY, S. Status report on Musa nematode problems and their management in India. In: DE LA CRUZ, F. S. et al. Towards management of Musa nematode in Asia and the Pacific. Los Baños, Philippines: Inibap, p.3-75, 2003. 